\title{
The Development of a Model for Complaint Delivery on Aviation Industry in Indonesia Based on SMS Gateway to Promote Flight Safety
}

\author{
Riani Nurdin ${ }^{1,}{ }^{*}$, Eko Poerwanto${ }^{1}$, Haruno Sajati² \\ 1 Department of Industry Engineering, Sekolah Tinggi Teknologi Adisutjipto, Jalan Janti Blok. R, Lanud \\ Adisutjipto, Karang Janbe, Daerah Istimewa Yogyakarta 55198, Indonesia \\ 2 Department of Informatics, Sekolah Tinggi Teknologi Adisutjipto, Jalan Janti Blok. R, Lanud Adisutjipto, \\ Karang Janbe, Daerah Istimewa Yogyakarta 55198, Indonesia \\ * Correspondence: rianinurdin@gmail.com
}

Received: 7 September 2019; Accepted: 25 October 2019; Published: 30 December 2019

\begin{abstract}
The variety of complaints appearing on Aviation Industry in Indonesia actually indicates the existence of problems on aviation system in Indonesia. The number of complaints may serve as an early detection in a system before the occurrence of an accident in a flight. Increasing numbers of flight service users in Indonesia had not been supported with an adequate complaint delivery, whether it is for internal complaints or external ones. One of available solutions is to detect whether all system components on Aviation Industry in Indonesia is good or not. In an effort to enhance system performance, a model for integrated complaint delivery is developed on Aviation Industry based on SMS Gateway in Indonesia. The model is expected to become a data bank on Aviation Industry to ease controlling, evaluating and improving condition performance on flight systems. This research used comparative and descriptive methods. It also results in applied product hence it is expected that the output can be used to complement the current product/program operated by Directorate General of Civil Aviation (DGCA). The development of a model for complaint delivery is conducted to make cellular phone numbers inputs for all stakeholders on aviation industry. This strategy activates all stakeholders to provide information regarding the current conditions for all subsystems in flight system in Indonesia
\end{abstract}

Keywords: complaint delivery, SMS gateway, flight safety

\section{Introduction}

At present, Directorate General of Civil Aviation has State Safety Program (SSP). It is a program with a goal to promote the prevention of accident with data analysis of accidents and incidents supported by rapid information exchange. The program had been ratified into Law No. 1 Year 2009 regarding Aviation. Unfortunately, the program does not run optimally due to the inactivity in information delivery, whether it is regarding complaint (service) or safety and security in aviation industry. In order to activate SSP, a development is conducted by making cellular phone numbers as inputs for all stakeholders on aviation industry, therefore they become an important data to be activated in SMS Broadcast with similar messages to be delivered to multiple recipient numbers at once. This strategy activates all stakeholders to provide information based on recent condition to all subsystems on aviation system in Indonesia.

One reason for the passivity of SSP system is the lack of data integration from stakeholder closest to the users, namely the operator. Operator can act as a data collector where flight service 
users (passengers) fill phone number to use in SMS broadcast to inform government programs on the field of air transportation. Nevertheless, data integration process is vulnerable to system interoperability issues and data security, thereby the proposed system in this research is an active, integrated secure one.

Integration process being conducted considers system heterogeneity factor. Operator develops application on different platforms and with different programming languages, hence it is very necessary to create an acceptable agreement (standard) from the provider to the consumer. This standard is embodied on a web service protocol, be it Simple Object Access Protocol (SOAP) or RESTful.

The model of complaint delivery information network on aviation industry which is developed on this research can be utilized to analyze condition and system performance of air transportation when a condition of flight accident occurs. Based on analysis results, further steps are taken to fix and improve system performance of all stakeholders on Aviation Industry in Indonesia as the backbone of development equalization.

\section{Literature Review}

Flight operator in this regard, an airline company, must ensure that airplane used to fly and flight crew operating it must conform to the assigned standard. This is done to provide a sense of security to the passengers. If this cannot be conditioned by an airline company, then the company starts losing the trust from its consumers gradually. According to the research done by other researcher [1]. It concludes that there is a negative relationship and significance between anxiety towards flight safety and decision to purchase Lion Air ticket. The effective contribution of anxiety toward flight safety to the decision to purchase Lion Air ticket is $11.5 \%$. One form of information services easily accessible and obtainable by passengers or candidate passengers is information via Short Message Service (SMS) because nearly everyone possessed mobile phone and can operate SMSbased application well.

Chaniago and Junaidi in [2] said, SMS Gateway is middleware service that enables SMS to send and receive messages from a communication device. This is also an ideal way to deliver software service in order to communicate automatically with end users by way of SMS channel, regardless of GSM telecommunication operator which provides SMS service. This SMS gateway makes use of modem to become an SMS sending server. SMS utilized cellular operator network to send SMS, while Gammu service acts as software for SMS Gateway and it is integrated with MySQL database.

Saleem and Doh in [3] conducted a research with the title "Generic Information System Using SMS Gateway" which developed a system that presents multipurpose information and it had successfully been used to provide different information for different companies. It is a less expensive way to deliver useful information for the users located on areas without internet connection. The system can be further expanded not only to deliver information but also to process transaction based on user's SMS. Qiu, Liu Zhao in [4] said that data integration process involves heterogeneous system from programming language used in developing the application, operation platform, system management database and communication protocol. These differences had made the process of data sharing complicated, inefficient and vulnerable to security breach. Therefore, a protocol to enable data integration from heterogeneous system effectively and securely is needed.

In recent years, the emergence of technology-based distributed object model to resolve the problem of data exchange had resulted in many distributed computation technologies. These distributed objects are: Java RMI (Remote Method Invocation), DCOM (Distributed Component Object Model) and CORBA (Common Object Request Broker Architecture). However, they had many unresolvable weaknesses. 
Web Services are based on one set of industry standard that are widely accepted and not limited to Extensible Markup Language (XML), Simple Object Access Protocol (SOAP), Web Service Description Language (WSDL) and Universal Discovery, Description, Integration (UDDI).

Souza and Puttini in [5] elaborated that this security problem involves three stakeholders, namely provider, consumer and end user. Each one of these stakeholders has different interest. Provider and consumer want a secure system to integrate data through public lines while end user needs privacy so that their data are not misused by third parties.

Based on above literature review, hence information network based on SMS Gateway can be developed for complaint delivery on aviation industry in Indonesia. Complaint data on aviation industry are needed so much to fix, correct and evaluate the operation of flight systems, so that the preventive measures can decrease the rate of flight accident in the end.

\section{Research Methodology}

\subsection{Research model}

The research of model development for complaint delivery on aviation industry is a continuation from a program operated by Directorate General of Civil Aviation, namely SSP, thereby the research method is comparative and descriptive. State Safety Program (SSP) pioneered by ICAO had a voluntary reporting system with a goal to accommodate all reports from nonmandatory users, especially the community of air transportation service users. The report is accommodated with SMS technology in order to be affordable to all user levels. SMS is a basic technology that nearly everyone is capable to use it. The report sent by a non-mandatory user is accepted by SMS service which is subsequently stored in a database so that it can be processed into a valid information at a later time.

SSP program facilitates actual information collection related to flight safety potential. The system that can be accessed at http://ssp.hubud.dephub.go.id contains two reporting systems. Mandatory Occurrence Report is written in a provision of ICAO Annex 13 Chapter 8. This provision contains the rule that members of ICAO are obliged to provide an incident reporting system. The obligatory reporter in this regard is:

1. Airline

2. Maintenance Repair Overhaul (MRO)

3. Air Navigation (AirNav)

4. Flight Crew 5. Airport Manager

\subsection{Voluntary Confidential Report}

Voluntary Confidential Report is used to contain information not covered in mandatory reporting. This type of report is done by all flight stakeholders and in the case where Mandatory Reporting cannot be performed, it became obligatory. In general, reporting system in this SSP can be illustrated on the following context diagram Figure 1.

There are several factors that contributed to the general problem where the system does not run optimally:

1. The lack of dissemination about this SSP program, whether it is aimed at mandatory reporter or voluntary one.

2. The user is obliged to register first before being able to report an incident.

3. User's fright toward law sanction from a given report despite being clearly written in Indonesian Government Law No. 1 Year 2010 that the reporter is protected, though unfortunately the protective regulation is not yet ratified. 


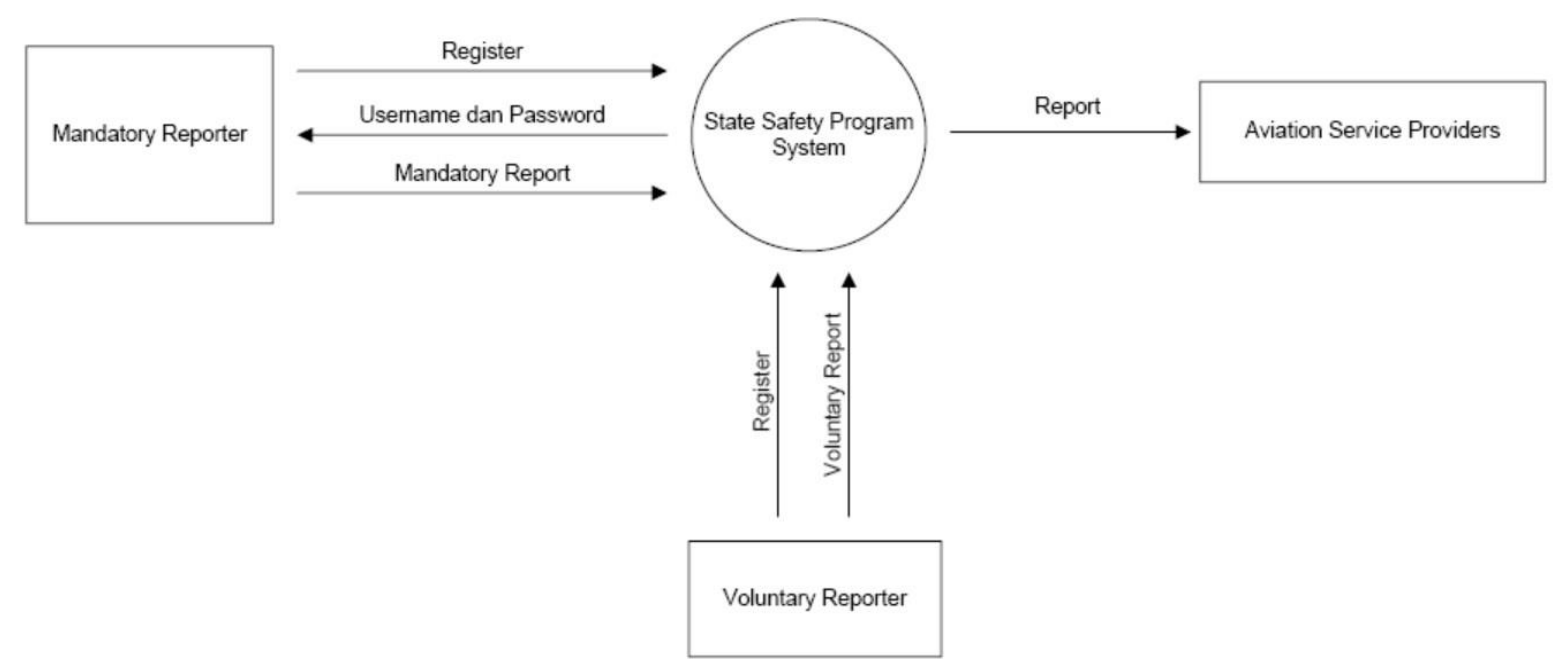

Figure 1. SSP System Context Diagram

The problem that emerges due to the lack of dissemination and complexity of registration process can be overcome if the running system had been integrated into one of systems involved in air transportation, such as ticket sales, personnel information and others systems that contain all users of this SSP. For example, ticket sales system that contains user data as the lowest level of stakeholder from Aviation Service Provider.

\section{Results and Discussion}

If data from a passenger (validated at check-in process) is readable by SSP, the running system can broadcast the information regarding the existence of SSP program to the passengers by using Short Message Service (SMS) while at the same time register them as users so that they can just reply the message as a form of reporting. Data integration takes the form as shown in context diagram is as indicated on Figure 2 below.

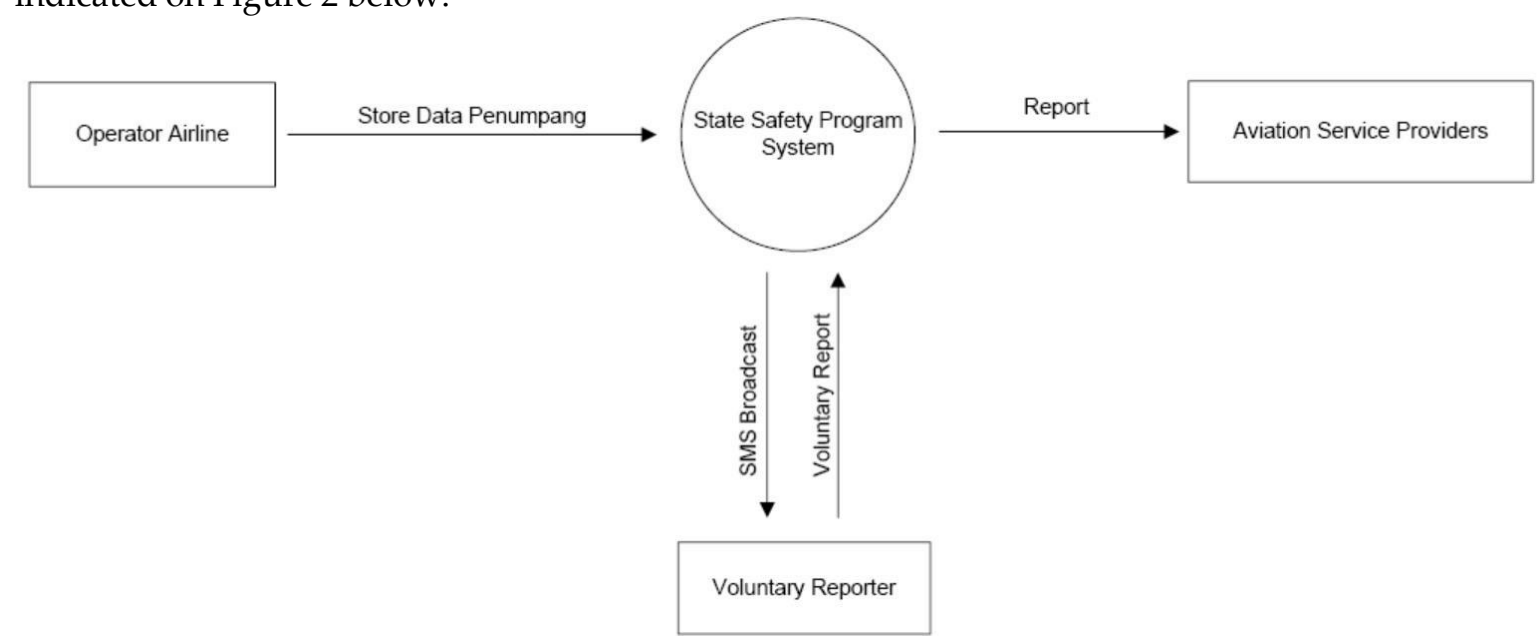

Figure 2. Context Diagram of Proposed Voluntary Reporting System

Regarding mandatory reporting system, this SSP program can work together with institution / third parties, such as maintenance technician and so on, that store personnel data, especially the employee having obligation to report the event of airplane incident. 
In order to support communication among systems, web service supporting interoperability at data level can be used. The web service can utilize eXtensible Markup Language (XML) or JavaScript Object Notation (JSON). This communication is regulated to use Simple Object Access Protocol (SOAP) or Representational State Transfer (REST). These two protocols enable data communication by using Hypertext Transfer Protocol (HTTP) which is commonly used in Internet. This data exchange uses open network (public) with a potential of unauthorized data access. To circumvent this, data can be encapsulated with certain technique in order to maintain its confidentiality. For example, by using Rivest Chipper 3 data encryption so that XML data is seen as in Figure 3

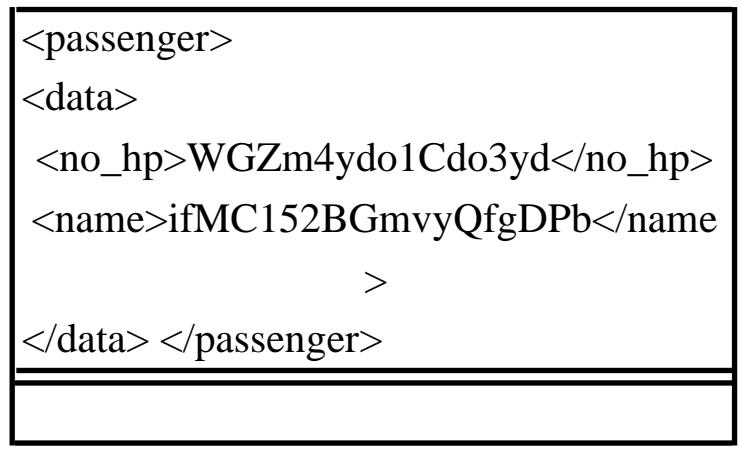

Figure 3. Encrypted XML Data

From both context diagrams (mandatory and voluntary reporting), the complete context diagram (Level 0 Data Flowchart) can be illustrated on Figure 4 below:

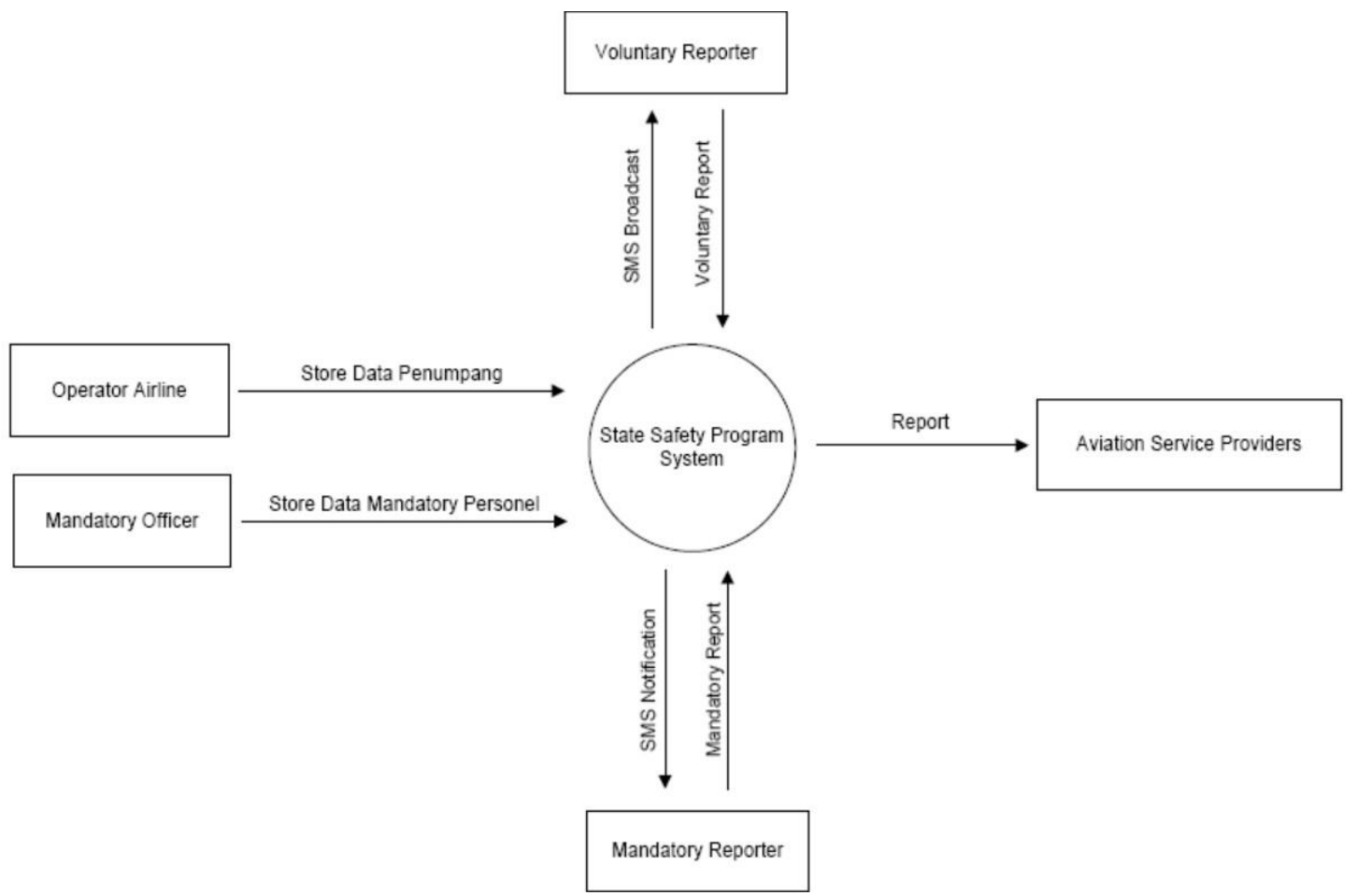

Figure 4. Level 0 Data Flowchart

The advantages of this system are:

1. Mandatory and voluntary reporter does not need to register first before being able to report. The registration is handled by a backend process and it is not performed by user, in this case, the reporter. 
2. Mandatory reporter still needs to have a username and a password since the report that is delivered via web portal is more credible in nature.

3. To stakeholders, in this case regulators, now have mechanism to disseminate follow-up programs or new regulations regarding aviation to the community.

\subsection{SMS Gateway with Auto-Reply Service}

Auto-Reply service can be utilized as a substitute for SMS operator so that response of the system can be much quicker. In this research, Auto-Reply service will only be used to inform the voluntary reporters that their reports have been accepted by the system.

\subsection{Viewing Voluntary Report}

Voluntary report can be accessed by operator and the person in charge of the program. The duty of the operator is to:

1. Reply the message which needs a prompt response.

2. Import data from other system by using web service

The menu of Report SMS is located on the navigation section. This service is used to view the contents of voluntary report accepted by the system. To view the recapitulation of report numbers, PIC can choose the menu Report Number Recapitulation Chart on navigation bar then a chart of report numbers will be shown such as the one on Figure 5 below:

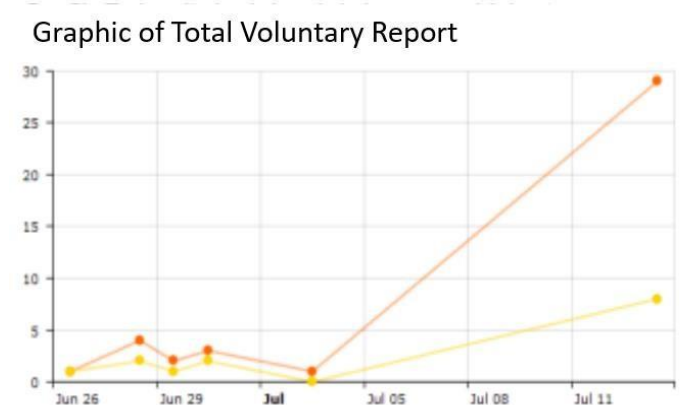

Red line is the receiving report Yellow line is the responded report
Graphic of Total Mandatory Report

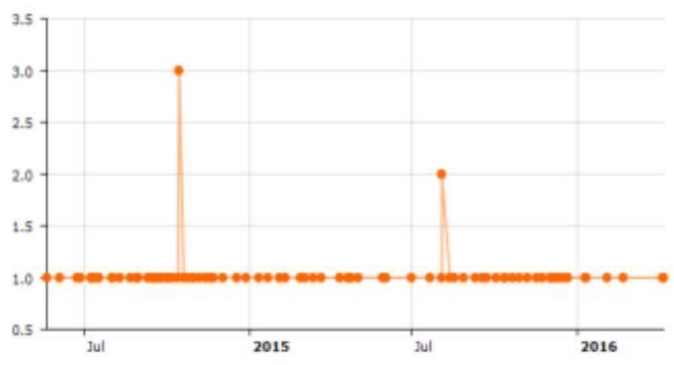

Red line is the receiving report

Figure 5. Report number based on SPS recapitulation chart

\subsection{Viewing Mandatory Report}

On mandatory report, accepted report is originated from assigned PIC on each institution. PIC data are saved on mandatory report table which is related to mandatory reporting tabel. This report contains:

1. Date of Report

2. Operator Name

3. Airport Name

4. Incident Report

5. Airplane Type

6. Location of Airplane Registration

7. Number of Air Crew

8. Number of Passenger

9. Number of Victim

10. Incident classification, that consists of incident, serious incident. 
In order to make the reading of mandatory report easier, mandatory messages are grouped according to the department, incident type and every message is given different color that matches to the incident classification, i.e. yellowish blue for incident, blue for serious incident and red for accident.

\subsection{Integration of SSP Data with Stakeholder}

If the system being developed can be integrated with another one, such as passenger manifest data from airline, SSP data can be supported by that system as respondent data. The process of importing data can be performed by using web service concept with data format of eXtensible Markup Language (XML), Javascript Object Notation (JSON) or Comma-Separated Value (CSV).

In order to enable data entry from operator, at first the operator (airline) must present data in the format understandable by SSP system. Any database platform being used by operator must be changed into data that are accessible from SSP system. These data may have XML, JSON or CSV format.

The problem arising from web service method is security issues where data being provided by operator are sent through public lines where unauthorized party is also able to access them. The problem can be overcome by encrypting presented data on the first place so although data are accessible by third parties, they will be un-intelligible. The encrypted information must be able to be reversed into data that can be understood by the SSP application with decryption method such as shown on Figure 6.

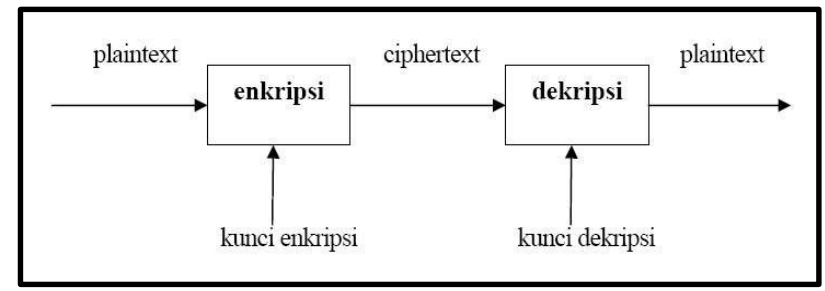

Figure 6. The Process of Encrypting and Decrypting Passenger Data

Mathematically, encryption process (E) is written in the formula:

$$
\mathrm{E}(\mathrm{M})=\mathrm{C}
$$

While decryption process $(\mathrm{D})$ is written in the formula:

$$
\mathrm{D}(\mathrm{C})=\mathrm{M}
$$

Where:

$$
\begin{aligned}
& \text { M: Plain text (Appeared message) } \\
& \text { C: Cypher text (Encrypted Message) }
\end{aligned}
$$

SSP operator can just types in URL address of JSON data that has been prepared inside the import form by an operator as shown and press Import Data button.

\subsection{Mass Message Broadcast}

Mass information broadcast is indispensable to distribute information, whether it is regarding community service or new program/regulation by Ministry of Transportation. The required data for mass information broadcast are cell phone numbers of the people that can be obtained from airline when they purchased the tickets, from Ministry of Communication and Informatics when the people register their SIM starter kit or alternatively, from voluntary reporting as explained before. 


\section{Conclusion}

Based on all elaboration in previous chapter, there are some conclusions regarding development research of the model for complaint delivery on aviation industry as the initial model on State Safety Program (SSP) is developed to become a more proactive system by inputting cell phone numbers of all stakeholders in aviation industry, be it mandatory ones or voluntary ones, to enable SMS broadcast. The developed SSP can be used as database for monitoring, analysis and evaluation activity upon system performance of national aviation industry through systematic reporting. The separation of data/information on SSP is between complaint service and flight safety. Hence, information service can be more practical when it comes to composing performance report on flight safety system as a whole for all involved stakeholders.

\section{Acknowledgment}

This research is supported by Ministry of Research, Technology and Higher Education through the program of Competitive Grant/Applied Product. This research is also supported by the institution of Sekolah Tinggi Teknologi Adisutjipto Yogyakarta. The authors would like to express sincere gratitude to these two institutions.

\section{References}

[1] Sari, Desti Puspita, 2010, Hubungan Antara Kecemasan Terhadap Keselamatan Penerbangan Dengan Pengambilan Keputusan Membeli Tiket Penerbangan Domestik Lion Air Pada Penumpang Di Bandara Ahmad Yani Semarang, Fakultas Psikologi, Universitas Diponegoro, Semarang.

[2] Chaniago, M.B. \& Junaidi, A, 2016, SMS Gateway and Barcode Technology for Presence of Students in SMK Unggulan Terpadu PGII Bandung: a Case Study, Cyber and IT Service Management, International Conference on DOI: 10.1109/CITSM.2016.7577576.

[3] Saleem \& Doh, 2009, Generic Information System Using SMS Gateway, Fourth International Conference on Computer Sciences and Convergence Information Technology; 978-0-76953896-9/09 @ 2009 IEEE DOI 10.1109/ICCIT.2009.99.

[4] Qiu Decheng, Liu Junning, \& Zhao Guoying, 2016, Design and application of data integration platform based on web services and XML, 6th International Conference on Electronics Information and Emergency Communication (ICEIEC) DOI 10.1109/ICEIEC.2016.7589732 Print ISBN New-2005_CD_978-1-5090-1995-3.

[5] Souza, Stefano M P C., and Puttini Ricardo S, 2016, Client-side encryption for privacy-sensitive applications on the cloud, 2nd International Conference on Cloud Forward: From Distributed to Complete Computing Volume 97, Pages 126-130.

(C) 2019 by the authors. Submitted for possible open access publication under the terms and conditions of the Creative Commons Attribution (CC BY) license (http://creativecommons.org/licenses/by/4.0/). 